\title{
Scarcity in the time of over-consumption
}

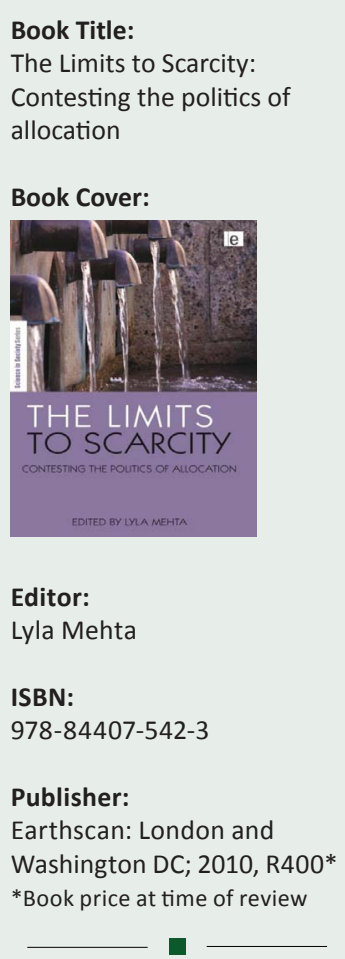

Review Title:

Scarcity in the time of overconsumption

Reviewer:

Wendy Annecke ${ }^{1}$

\section{Affiliation:}

${ }^{1}$ Cape Research Centre, South African National Parks, South Africa

Email:

wendy.annecke@sanparks. org

Postal address:

PO Box 216, Steenberg 7947,

Cape Town, South Africa

How to cite this book review: Annecke, W., 2012, 'Scarcity in the time of overconsumption', Koedoe 54(1), Art. \#1089, 2 pages. http:// dx.doi.org/10.4102/koedoe. v54i1.1089

(C) 2012. The Authors. Licensee: OpenJournals Publishing. This work is licensed under the Creative Commons Attribution License.
Resource use and the sustainability of resources constitute a significant concern for many scientists and field staff in South African National Parks (SANParks). According to its mission 'to develop, manage and promote a system of national parks that represents biodiversity and heritage assets by applying best practice, environmental justice, benefit sharing and sustainable use', SANParks is committed to sharing the benefits of the areas it protects with the wider society. This wider society, in immediate terms, primarily incorporates tourists and the communities living on park borders. Tourists require access to resources such as roads, water, energy, food and waste facilities, whereas people living on the boundaries of the parks require access to grazing, medicinal and food plants, wood fuel and bush-meat. Consequently, some of the biodiversity resources that SANParks was established to protect, are under severe pressure from 'the wider society' in general. For example many medicinal plants are threatened by over harvesting (both legal and illegal), whilst other resources, such as water, are threatened by pollution, changes in land use and increased demand for these. This book will be of interest to conservationists who are concerned with the ethics and sustainability of resource use, as well as the status of biodiversity health in the parks.

The Limits to Scarcity does not provide answers to the difficult issues arising with regard to resource use, but it does provide a different way of thinking about scarcity and why this occurs. In doing so it raises questions about who the primary resource users are, and encourages a shift in perspective about the rights of all users.

The Limits to Scarcity is compiled from of a series of papers delivered at a conference on 'Scarcity and the politics of allocation' held at the Institute of Development Studies, at the University of Sussex, in June 2005. The fourteen chapters are divided into three parts with each part preceded by an introduction and commentary by the editor, Leyla Mehta. The guidance she provides is useful for novice readers in the field of scarcity or for readers with limited time. Each chapter explores the notion of scarcity from a different angle and includes how the notion of scarcity is constructed and whose purposes it serves. The three chapters in Part I discuss why scarcity matters, Part II explores the different perspectives of scarcity within economics and Part III investigates the politics of scarcity in case studies of water, energy and food supplies. Authors include well known Nicholas Xenos, Fred Luks and Ben Fine. The latter is better known to most South Africans for his and Zavareh Rustomjee's seminal work on the Minerals-Energy-Complex.

The Limits to Scarcity makes an important contribution to resource use debates, particularly in the light of the rampant consumer culture which is seen by most people as the only way out of the ongoing global economic woes. Chapter by chapter the book unpacks the dynamics of how resources are allocated in various societies: who has access to what resources, and under what circumstances. The authors are careful to acknowledge the 'biophysical realities of falling groundwater levels, melting icecaps and declining soil fertility' (Mehta 6) whilst they dissect the politics of need and those involved in the access and allocation of resources. The book has chapters of interest to economists (such as that by Fine), engineers (such as that by Lankford) and to philosophers and non-economists (Xenos). For those interested in social justice and equitable societies as well as those involved in development and the poverty industry, there is plenty of significant content over which to ponder. What is most disturbing about this book is the evidence demonstrating how allpervasive neo-Malthusian economics has become, even in 'development thinking'.

In the first chapter, Mehta provides a historical overview about the legacy of and approaches to normalizing the 'scarcity postulate'. This overview sets the tone for the rest of the book by demonstrating that scarcity is not necessarily a natural or universal concept. She offers the chapters that follow as evidence for her argument as well as her challenge to the inertia evident in much mainstream thinking and economics. The ensuing chapters provide ample evidence that there is enough water, energy and food for everyone in the world (FAO 2000 in Hilyard 2010:152). One has only to visit the landfill sites and the dump pickers industry in South Africa to observe the magnitude of waste generated by society, but, as Raynor (p. xviii) argues, scarcity has become 
a rationale for the inequitable allocation of resources: it constitutes a gate-keeping mechanism. Fine (p. 82) follows this up by asking uncomfortable questions about the manner in which a society chooses to rank one person's welfare over another; their criteria for selecting one group of users who are able to access resources easily and use them intensely, whilst another group may have only minimal access to the same resources. I would suggest that feminists have become adept at conducting analyses that evaluate access to, control over and benefits from resources, and that feminist literature could contribute to this debate and perhaps shift its dynamics.

In Dipak Gyawali and Ajaya Dixit's Chapter 13, scarcity is highlighted as a modern concept driven by technological choices to meet specific socio-political needs (p. 234). The authors quote Helena Norberg-Hodge who worked in Laddakh when there was no word for 'poor' in that region, but on returning some ten years later, they found her former translator pleading poverty and that his country desired a western notion of development. He and his countrymen (and women) had fallen victim to the notion of wealth that emanates from material goods.

There are chapters on soil fertility in Africa, agriculture and hunger, and two chapters for those involved in the water sector and the shared responses to its scarcity. The editor, Mehta, has herself worked extensively on issues around water scarcity and is well known in this field. Bruce Lankford argues, in Chapter 11, that water scarcity should not only be understood as 'volumetric imbalance to be dealt with by saving, storing and delivering more water' but suggests a framework for supply, demand and shared responses. He highlights how the natural and social scarcity of water can be exacerbated by people and institutions that are not designed to react to the rapidly occurring variations in water scarcity, in time and space, and provides a table comparing approaches for managing the dynamic supply of water in sub-catchment areas. From this he draws a number of conclusions, that provide persuasive arguments for the adoption of his composite and complex framework.
In Chapter 12, Jasveen Jairath re-examines the meaning and explanations of water scarcity and critiques what he calls the 'conceptual weakness and politics' of Integrated Water Resource Management. He highlights the importance of historical conditions, suggests the kind of questions that should be asked when bringing the weak and the strong together at a table, and points out that the democratic governance of water is seldom achieved.

Whilst the concept of scarcity itself is thoroughly unpacked, the book is weak on recommendations about how mainstream and pervasive thinking might be changed from valuing over-consumption to valuing sufficiency. Xenos argues that historically the time for appealing to the morals and ethics of a society appears to be over. Such appeals did not, for example, win the friends and support that President Carter had hoped for in 1979. Likewise, in South Africa, appealing to the adherence to ex-President Mandela's values has worn thin. The question is what could provide the impetus for change? Whilst none of the authors define the term 'enough', some point to individuals and communities that have described it for themselves: the Amish and Po Chi-I are mentioned in this regard. I particularly like the words of Po Chi-I, the retired mandarin who wrote poetry, from about 850 AD, (in Thompson 2010):
What I shall need are a very few things.
A single rug to warm me through the winter;
One meal to last me the whole day.
It does not matter that my house is rather small;
One cannot sleep in more than one room!
It does not matter that I have not many horses;
One cannot ride two horses at once! (p. 131)

There are typing errors throughout the book including the sub-title of a book in the Science in Society Series: Participation and Exalusion in Nuclear Decision-making. Mehta herself thanks the Science and Society Programme - this name is an unlikely change from the series name and there are various other errors that should have been noticed and corrected. Nonetheless, these issues should not detract from a provocative and worthwhile book. 